О. Н. Кушнир, И. А. Мартюшев

Сыктывкар, Россия

\title{
ДОКУМЕНТНАЯ КОММУНИКАЦИЯ В КОНТЕКСТЕ ЛИНГВИСТИЧЕСКОЙ
}

\section{ЭКСПЕРТИЗЫ}

В статье рассматривается проблема, находящаяся на стыке документоведения, лингвистики и юриспруденции, - проблема качества текстов официальных документов, прежде всего - документов, обладающих юридической силой. Классификащия документов на официальные и иные проводится на основании свойства документа воздействовать на правоотношения, или иметь юридическую силу. Применяемое в документоведении понятие «юридическая значимость документа» применимо как к официальным, так и к иным документам. По мнению авторов, принципиальным различием между указанными свойствами документов является временна́я соотнесенность самих процессов возникновения документа и возникновения события или действия, с которым документ связан юридической силой или юридческой значимостью: юридическая сила связывает документ с событиями или действиями, которые наступают, как правило, после издания документа, а юридическая значимость связывает документ с произошедшими событиями / совершенными действиями. Грань между двумя процессами, вызывающчим проявление указанных свойств документа, весьма зыбкая. При этом один документ может обладать одновременно и юридической силой, $и$ юридической значимостью. Предметом лингвистической экспертизы чаще всего становятся тексты официальных документов, которые обладают юридической силой, поскольку их собственно правовая и сочиальная значимость выше, чем у всех других документов. Но и само свойство юридической силь у разных видов документов различно и зависит от правового статуса и компетенции автора (авторов) документа, а также от функционального назначения документа. В практике лингвистической экспертизы документных текстов различают экспертизу, проводимую на стадии проектирования текста документа, и экспертизу, проводимую на стадии его применения: в первом случае проявляется превентивная функция лингвистической экспертизы, во втором - детективная. Лингвистическая экспертиза документных текстов, по заключению авторов, должна получить четкий институциональный статус в документной коммуникации и в системе государственного и муниципального управления, $и$ на корпоративном (локальном) уровне.

Ключевые слова: документный текст, лингвистическая экспертиза, юридическая сила документа. 
Сведения об авторе: Ольга Николаевна Кушнир, доктор филологических наук, директор института гуманитарных наук Сыктывкарского государственного университета. 167001, Сыктывкар, Октябрьский пр., 55, 4-й корп. СГУ, к. 205. E-mail: info17275@mail.ru.

Сведения об авторе: Иван Анатольевич Мартюшев, обучающийся по направлению подготовки магистратуры 45.04.01 Филология ФГБОУ ВО «Сыктывкарский государственный университет имени Питирима Сорокина». 167001, Сыктывкар, Октябрьский пр., 55, к. 220. E-mail:167982@gmail.com.

O. N. Kushnir, I. A. Martyushev

Syktyvkar, Russia

\section{DOCUMENT COMMUNICATION IN THE CONTEXT OF LINGUISTIC EXPERTISE}

The article discusses the problem at the junction of records management, linguistics and jurisprudence - the problem of the quality of texts of official documents, first of all - documents that have legal force. Classifying documents into official and other is based on the property of the document to influence legal relations, or to have legal force. The notion of «legal value of a document» applied in records management is applicable both to official documents and to other documents. According to the authors, the fundamental difference between the indicated properties of documents is the temporal correlation of the processes themselves: the appearance of the document and the occurrence of an event or action with which the document is linked by legal force or legal value: the legal force links the document to events or actions that occur, as a rule, after enaction of the document, and the legal value links the document to the events that occurred/actions committed. The line between the two processes that cause the manifestation of the specified properties of the document is very unstable. At the same time, one document can have both legal force and legal value. Texts of official documents that have legal force most often become subjects of linguistic expertise, since their own legal and social value is higher than that of all other documents. But the very property of legal force in different types of documents is different and depends on the legal status and competence of the author (authors) of the document, and on its functional purpose. In the practice of linguistic expertise of document texts, one distinguishes the expertise carried out at the design stage of the text of the document and the expertise carried out at the stage of its application: in the first case, the preventive function of the linguistic expertise is manifested, in the second case- the detective. Linguistic expertise of document texts, according to the authors' conclusion, should receive a clear institutional status in document communication and in the system of state and municipal management, and at the corporate (local) level.

Key words: document text, linguistic expertise, legal force of a document. 
About the author: Olga Nikolayevna Kushnir, Doctor of Philological Sciences, Director of Institute of Human Sciences at Syktyvkar State University named after Pitirim Sorokin. prospect Oktyabrskiy,d.55, korpus 4, office 205,Syktyvkar,167001.E-mail: info17275@mail.ru.

About the author: Ivan Anatolievich Martyushev a full-time postgraduate student of training program 45.04.01 «Philology» at Syktyvkar State University named after Pitirim Sorokin. prospect Oktyabrskiy,d.55, korpus 4, office 205, Syktyvkar, 167001.E-mail: 167982@gmail.com.

В настоящее время отмечается активный рост интереса со стороны государства и общества к документной коммуникации и к документу как феномену социальных взаимоотношений. Обусловлено это прежде всего увеличением разнообразия прагматических обстоятельств, в которых функционирует документ, проблемами и противоречиями документной практики и возрастанием значимости самих документных процессов. При этом, помимо сугубо документоведческих аспектов, характеризующих формальную сторону документной коммуникации (понятие документа и его сущность, видовая классификация документов и функциональные свойства различных видов документов, правила делопроизводства и особенности отдельных документных процессов), значимыми оказываются ее лингвистические составляющие (содержательно-смысловые аспекты). Такая ситуация ставит перед учеными и практиками ряд актуальных вопросов, в том числе критерии выбора текстовых единиц, особенности их организации в документных текстах, оценка лингвистической составляющей документирования и др.

Одной из наиболее значимых проблем, находящихся на стыке документоведения, лингвистики и юриспруденции, является проблема качества текстов официальных документов, особенно таких, которые способны своим действием повлиять на деятельность граждан и юридических лиц, другими словами - документов, обладающих юридической силой. Внешне способность таких документов воздействовать на сознание, волю и поведение отдельных людей проявляется в форме уяснения и интерпретации отдельных языковых элементов документных текстов и всей их совокупности с целью выбрать модель поведения и конкретные действия. Ключевое действие по 
интерпретации, с одной стороны, носит очевидную субъективную оценку, поскольку зависит от интеллектуальных возможностей интерпретаторов (образованность, уровень культуры, в том числе правовой), с другой стороны, оно в значительной степени зависит от того, насколько автор документа доступно, точно и однозначно составил текст, то есть оправданы ли выбранные им языковые средства, их организация самой целью документной коммуникации.

Очевидно, что следует уделять серьезное внимание лингвистическим параметрам качества документного текста (термин С. П. Кушнерука, см.: [Кушнерук 2007]) на стадии его проектирования, что и реализуется в проведении лингвистической экспертизы проектов документов. Не менее важна лингвистическая экспертиза и на стадии применения документа. В этом случае она проводится в целях разрешения уже возникшего конфликта.

Документные тексты можно классифицировать по разным основаниям. В контексте лингвистической экспертизы значимым основанием является классификация документных текстов по видам документов, к которым они относятся. При этом обнаруживается, что качественные различия между видами документных текстов обусловлены главным образом их функциональным назначением [Бунчук и др. 2016].

Всю совокупность создаваемых документов можно разделить на две группы: официальные документы и иные документы. Официальный документ определяется как документ, созданный организацией, должностным лицом или гражданином, оформленный в установленном порядке [ГОСТ Р 7.0.8-2013]. Таким образом, основным классификационным признаком официального документа является наличие определенных правил его оформления и функционирования. При этом требования к оформлению документа могут содержаться в законах, подзаконных нормативных правовых актах, предусматриваться нормативными актами коммерческих и иных организаций.

С позиций юриспруденции, важно еще одно свойство официального документа - его способность воздействовать на правоотношения [Першин 
2016; Бриллиантов 2010]. Такая способность официального документа определяется как его юридическая сила, то есть свойство официального документа вызывать правовые последствия [ГОСТ Р 7.0.8-2013], а именно: возникновение, изменение или прекращение у субъектов права определенных (потенциальных или реальных) прав или обязанностей. В контексте сказанного будет справедливым заметить, что юридическая сила корреспондирует с прагматическим функциональным назначением документа. Важно также подчеркнуть, что юридической силой обладают только официальные документы, которые в юриспруденции принято называть правовыми актами.

Добавим, что в документоведении применяется и понятие «юридическая значимость документа», определяемое как свойство документа выступать в качестве подтверждения деловой деятельности либо событий личного характера [ГОСТ Р 7.0.8-2013]. Юридической значимостью могут обладать как официальные, так и иные документы. Документы, обладающие юридической значимостью, в свою очередь, могут являться основанием для дальнейшего возникновения, изменения или прекращения правоотношений.

C некоторой долей условности можно согласиться с мнением В. Ф. Янковой о синонимичности понятий «юридически значимый документ» и «подлинный документ». Исследователь считает, что разграничить юридическую силу и юридическую значимость документа можно в полной мере лишь для электронных документов, тогда как для документов на бумажном носителе разграничение этих двух свойств не является существенным [Янковая, URL].

На наш взгляд, принципиальным различием между юридической силой и юридической значимостью документов является временна́я соотнесенность двух процессов: возникновение самого документа и возникновение события или действия, с которым документ связан юридической силой или юридической значимостью. Юридическая сила связывает документ с событиями или действиями, которые наступают, как правило, после издания документа (например, стороны договора наделяются установленными в 
договоре правами и обязанностями только после его заключения). Юридическая значимость связывает документ с произошедшими событиями / совершенными действиями (например, бухгалтерский отчет содержит информацию о финансовой деятельности, которая уже фактически имела место).

Таким образом, документы, обладающие юридической силой, создаются для возникновения событий в перспективе, а документы, обладающие юридической значимостью, создаются для подтверждения уже произошедших событий. Вместе с тем грань между этими двумя процессами весьма тонкая и не всегда очевидная, поэтому возможны ситуации, которые сопровождаются соответствующими документами, обладающими трудно разделимыми свойствами юридической силы и юридической значимости. При этом, бесспорно, один документ может обладать одновременно и юридической силой, и юридической значимостью.

Мы попытались определить виды официальных документов, обладающих юридической силой, классифицируя их по двум основаниям: по характеру юридического статуса автора документа и по характеру юридической силы документа. Такой подход ближе к юридическим наукам, не типичен, например, для документоведения, но объективен в свете лингвистической экспертизы документных текстов.

По характеру юридического статуса автора официальные документы можно разделить на: а) документы, создаваемые компетентными органами государственной власти и управления и должностными лицами Российской Федерация; б) документы, создаваемые компетентными органами государственной власти и управления и должностными лицами субъектов Российской Федерации; в) компетентными органами муниципального управления и должностными лицами местного самоуправления; г) юридическими лицами; д) физическими лицами. От компетенции органа или должностного лица, создавшего документ, напрямую зависит степень юридической силы документа. 
По характеру юридической силы официальные документы можно разделить на нормативные правовые акты и правовые документы ненормативного характера (правореализационные документы и правоприменительные акты).

Уточним дефиниции данных понятий: под нормативным правовым актом понимается письменный официальный документ, принятый (изданный) в определенной форме правотворческим органом в пределах его компетенции и направленный на установление, изменение или отмену правовых норм; под правовой нормой понимаются общеобязательные правила поведения, установленные или санкционированные государством и обеспеченные его принудительной силой [Большой юридический словарь, URL]. К последнему определению следует добавить, что правовая норма рассчитана на многократное применение. Правовые документы ненормативного характера правовых норм не содержат.

Правореализационные и правоприменительные акты объединяет то, что они влекут правовые последствия в отношении конкретных лиц, направлены на установление, изменение или прекращение конкретных правоотношений, либо содержат предписание однократного применения. Отличительная особенность правоприменительных актов состоит в том, что они имеют ярко выраженный властный характер, то есть их могут издавать лишь субъекты права, наделенные определенными властными полномочиями. При этом в теории государства и права также отмечается, что они издаются в случаях, когда нормативный правовой акт должен действовать с учетом тех или иных конкретных обстоятельств, требующих установления и контроля, когда есть спор о праве, правах и обязанностях, когда не исполняются обязанности, имеются препятствия в осуществлении права и при иных правонарушениях [Мелехин, URL].

Следует оговорить, что распределение видов документов по группам базируется на основе знакомства с реальной правотворческой и правореализационной практикой различных субъектов права, не всегда 
соответствующей научно-теоретическим (a $\quad$ в $\quad$ некоторых нормативным) основам. Речь идет о нередко встречающемся на практике несоответствии выбранного вида документа интенции автора в отношении его функционального назначения [Кушнир 2015; Лапина 2013; Лапина и др. 2013].

Предметом лингвистической экспертизы чаще всего становятся тексты таких официальных документов, которые обладают юридической силой, поскольку их собственно правовая (a, в конечном счете, и социальная значимость) выше, чем у всех других документов. Но и само свойство юридической силы у разных видов документов различно и зависит от правового статуса и компетенции автора (авторов) документа, и от его прагматического функционального назначения. На практике степень проявления юридической силы документа и степень достижения поставленной коммуникативной цели зависят также от правильного выбора вида документа, а также от соблюдения всех вытекающих из этого правил его составления и функционирования.

Итак, лингвистическая экспертиза юридических документных текстов как способ решения языковых проблем является особым видом прикладного лингвистического исследования, проводимого в соответствии с поставленными перед экспертизой целями. Исходя из возникающих прагматических потребностей, сложилось два вида лингвистической экспертизы: экспертиза, проводимая на стадии проектирования текста документа, и экспертиза, проводимая на стадии применения документа.

Лингвистическая экспертиза проектов документов (прежде всего, нормативных правовых актов разного уровня) заключается в оценке соответствия их текстов нормам современного русского литературного языка (с учетом особенностей юридического языка) с целью устранить грамматические, синтаксические, стилистические, логические, редакционно-технические ошибки и ошибки в использовании терминов. Функция такой лингвистической экспертизы - превентивная.

Второй вид лингвистической экспертизы заключается в обнаружении в тексте документа языковых ошибок и противоречий, обусловливающих 
возможность множественности интерпретаций его смысла, а также в установлении буквального смысла отдельных языковых структурнокоммуникативных микроэлементов. В данном случае реализуется детективная функция лингвистической экспертизы.

В проведении лингвистической экспертизы проекта документа заинтересован прежде всего сам субъект правотворчества. Интерес в проведении лингвистической экспертизы текста документа на стадии его применения может возникнуть у значительно большего круга субъектов.

Таким образом, лингвистическая экспертиза, будучи построенной на научно-ориентированной методологии и являясь востребованной процедурой в практике правотворчества и правоприменения, представляет собой действенный инструмент решения языковых проблем юридических документных текстов, а потому должна получить четкий институциональный статус в документной коммуникации не только в системе государственной власти и управления, но и на муниципальном и корпоративном (локальном) уровнях.

\section{ЛИТЕРАТУРА}

1. Большой юридический словарь: электронное издание. URL: http://petroleks.ru/dictionaries/dict_big_law14.php

2. Бриллиантов А. Критерии официального документа. Уголовное право. 2010. № 5. C. 4-7.

3. Бунчук Т. Н., Ильина Ю. Н., Кушнир О. Н. Свойства документа как важный фактор лингвистической экспертизы документного текста. Вестник Череповецкого государственного университета. 2016. № 5 (74). С. 46-50.

4. Делопроизводство и архивное дело. Термины и определения: ГОСТ Р 7.0.8-2013. Национальный стандарт Российской Федерации. Система стандартов по информации, библиотечному и издательскому делу, утв. приказом Росстандарта от 17.10.2013 № 1185-ст. URL: http://www.gost.ru/wps/portal/pages.CatalogOfStandarts.

5. Кушнерук С. П. Документная лингвистика. Волгоград, 2007.

6. Кушнир О. Н. О взаимообусловленности текстов ведомственных правовых актов и внутренних документов организации. Деловой и публицистический стили в истории 
русского языка и культуры: сборник докладов II Международной научной конференции. Петрозаводск, 2015. С. 158-163.

7. Лапина М. А. Правотворческая функция исполнительной власти: предложения по совершенствованию. Российская юстиция. 2013. № 1. С. 4-7.

8. Лапина М. А., Долгих И. С. Ведомственное нормотворчество МВД России: анализ состояния и перспективы развития. Административное и муниципальное право. 2013. № 3. C. 233-239.

9. Мелехин А. В. Теория государства и права. СПС КонсультантПлюс. 2009. URL: http://www.consultant.ru/cons/cgi/online.cgi?req=doc\&base $=\mathrm{CMB} \& \mathrm{n}=16615 \# 0$

10. Першин А. Н. Официальные документы и их криминалистическая классификация. Информационное право. 2016. № 2. С. 8-12.

11. Янковая В. Ф. Проблема разграничения понятий «юридическая сила документа» и «юридическая значимость документа». URL: http://www.sekretariat.ru/article/210278-qqe-16m4-problema-razgranicheniya-ponyatiy-yuridicheskaya

\section{REFERENCES}

1. Big Dictionary of Law [Bol'shoj juridicheskij slovar': jelektronnoe izdanie]. URL: http://petroleks.ru/dictionaries/dict_big_law14.php

2. Brilliantov A. Criteria for an official document [Kriterii oficial'nogo dokumenta]. Criminal law. 2010. № 5. P. 4-7.

3. Bunchuk T. N., Ilyina J. N., Kushnir O. N. Document properties as an important factor in the linguistic expertise of document text [Svojstva dokumenta kak vazhnyj faktor lingvisticheskoj jekspertizy dokumentnogo teksta]. Bulletin of Cherepovets State University. 2016. № 5 (74). P. 4650.

4. Office work and archival business. Terms and Definitions: All-Union State Standard P 7.0.8-2013. National standard of the Russian Federation. System of standards on information, librarianship and publishing, approved by the order of Rosstandart from 17.10.2013 № 1185-ст. [Deloproizvodstvo i arhivnoe delo. Terminy i opredelenija: GOST R 7.0.8-2013. Nacional'nyj standart Rossijskoj Federacii. Sistema standartov po informacii, bibliotechnomu i izdatel'skomu delu, utv. prikazom Rosstandarta ot 17.10.2013 № 1185-st]. URL: http://www.gost.ru/wps/portal/pages.CatalogOfStandarts.

5. Kushneruk S. P. Document Linguistics [Dokumentnaja lingvistika]. Volgograd, 2007.

6. Kushnir O. N. On the interdependence of texts of departmental legal acts and internal documents of the organization [O vzaimoobuslovlennosti tekstov vedomstvennyh pravovyh aktov $\mathrm{i}$ vnutrennih dokumentov organizacii]. Business and publicistic styles in the history of the Russian 
language and culture: a collection of reports of the II International Scientific Conference. Petrozavodsk, 2015. P. 158-163.

7. Lapina M. A. Lawmaking function of the executive authorities: proposals for improvement [Pravotvorcheskaja funkcija ispolnitel'noj vlasti: predlozhenija po sovershenstvovaniju]. Russian Justice. 2013. № 1. P. 4-7.

8. Lapina M. A., Dolgih I. S. Departmental norm-setting of the Ministry of Internal Affairs of Russia: analysis of the situation and development prospects [Vedomstvennoe normotvorchestvo MVD Rossii: analiz sostojanija i perspektivy razvitija]. Administrative and municipal law. 2013. № 3. P. 233-239.

9. Melekhin A. V. Theory of State and Law. Second edition, supplemented and revised (Prepared for the ConsultantPlus system) [Teorija gosudarstva i prava]. Legal reference system ConsultantPlus. 2009.

URL: http://www.consultant.ru/cons/cgi/online.cgi?req=doc\&base=CMB\&n=16615\#0

10. Pershin A. N. Official documents and their criminalistics classification [Oficial'nye dokumenty i ih kriminalisticheskaja klassifikacija]. Information law. 2016. № 2. P. 8-12.

11. Yankovaya V. F. The problem of distinguishing between the concepts «legal force of the document» and «legal value of the document» [Problema razgranichenija ponjatij «juridicheskaja sila dokumenta» $\mathrm{i}$ «juridicheskaja znachimost' dokumenta»]. URL: http://www.sekretariat.ru/article/210278-qqe-16-m4-problema-razgranicheniya-ponyatiyyuridicheskaya. 